\title{
Bird flu sparks worldwide bid to prevent human pandemic
}

\section{Alison Abbott and David Cyranoski}

The outbreak of highly contagious bird flu that is sweeping Asia, and which has killed at least five people, has put the World Health Organization (WHO) on full alert.

WHO scientists are now pulling out all the stops to trace the origin of the virus, known as $\mathrm{H} 5 \mathrm{~N} 1$, and to develop vaccine candidates. The spectre of a new human influenza pandemic, similar to that which killed millions in 1918 , looms over their effort. Pandemics arise when bird or pig flu viruses jump the species barrier to humans and mutate into highly contagious forms.

The current bird flu outbreak, which has wreaked havoc among poultry in Vietnam, Japan and South Korea, is exceptionally worrying, says Albert Osterhaus, an influenza expert at Erasmus University in Rotterdam, the Netherlands. Bird flu outbreaks in the Netherlands and Hong Kong last winter were rapidly contained and led to the deaths of only three people (see Nature 422, 247;2003). But Osterhaus says that management of the current outbreak has been loose and surveillance inadequate. There is no sign that the outbreak is abating, and it may already have spread to birds in Cambodia or Laos, where surveillance is also lax.

Viruses that jump the species barrier tend to be highly pathogenic, as the new host's immune system has had no time to build up defences. Although dangerous, the viruses are not necessarily contagious because they are adapted to survive in their original host. But the greater the number of people who catch the flu, the greater the chance that the virus will mutate into a form that is easily transmitted between humans. As yet, human-to-human transmission does not seem to have occurred.

Scientists in Japan, Hong Kong and the United States have sequenced the genomes of viruses found in birds in Vietnam, Japan and Korea, as well as those isolated from Vietnamese patients who have died.

The genomic data could reveal where the virus first emerged, its path of transmission and mutation rate, and how to control the spread, says Masato Tashiro, a virologist at the National Institute of Infectious Diseases in Tokyo. "The strains are similar to that isolated from a 2003 Hong Kong victim," he adds.

The data are being pooled in the Influenza Sequence Database based in Los Alamos, Cali-

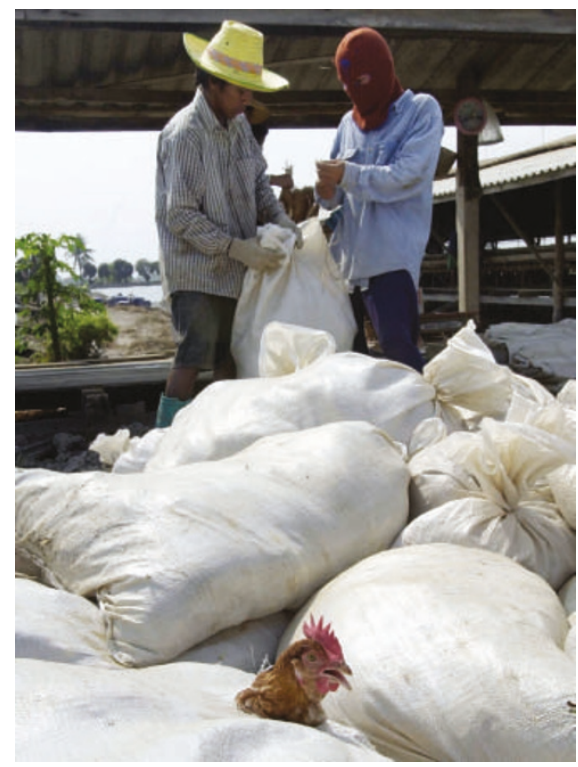

No escape: chickens are bagged up prior to burial in an effort to halt the spread of bird flu.

fornia, to aid development of human vaccine candidates. One candidate, made for the 2003 Hong Kong outbreak, is already being tested and if shown to be effective against the current strain will offer the effort a head start. "Should the few cases we are currently seeing in Vietnam turn out to signal a pandemic, we shall be ready for it," says Maria Cheng, a WHO spokeswoman based in Geneva.

\section{Director quits as cash cutbacks hit Californian labs}

Rex Dalton, San Diego

The California Institutes for Science and Innovation - four high-profile interdisciplinary facilities built at a cost of $\$ \mathbf{4 0 0}$ million - are going through a turbulent time just months before researchers move into the new buildings.

A bleak financial outlook, caused by fiscal difficulties at state level, is widely believed to have contributed to the departure of Marvin Cassman, head of one of the new facilities - the Institute for Bioengineering, Biotechnology and Quantitative Biomedical Research (QB3). Cassman, a former director of the US National Institute of General Medical Sciences who was appointed with much fanfare in 2002, quietly quit late last month and did not respond to requests for an interview.

The institutes are designed to channel expertise from across the University of California (UC) campuses into scientific discoveries that will spur statewide economic development. They were to have had an annual budget of at least $\$ 10$ million

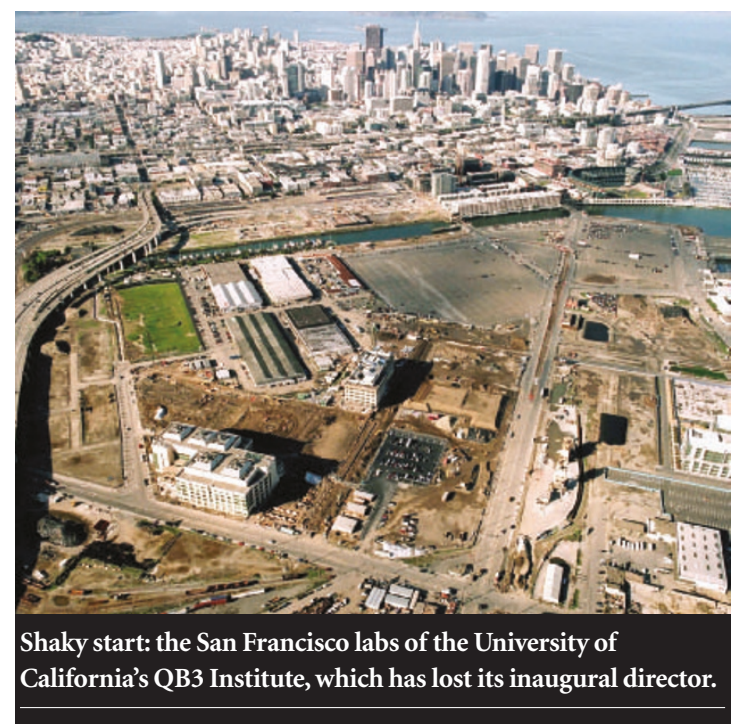

the researchers say they are confident that good science will still get done at the new facilities. But many fear that their efforts could be held back by problems with operating costs. Keith Yamamoto, a biochemist at UC San Francisco and executive vice-dean of the university's medical school, says the issue is of "grave concern".

At the California Institute for Telecommunications and Information Technology, based at the UC San Diego and Irvine campuses, director Larry Smarr says that they are "slowing down the growth" of programmes and may not initially occupy the entire new San Diego building. Administrators at the campuses that host the other two centres - the California NanoSystems Institute at Los Angeles and Santa

each for operating costs. But California is going through a fiscal crisis. The proposed budget for the next financial year, which will be finalized by July, cuts $\$ 370$ million from the total UC budget and hands the centres just \$1 million each.

Because scientists at the institutes will fund their research through external grants,

\section{Barbara and the Center for Information} Technology Research in the Interest of Society at four campuses - say that they will use university funds to pay the operating costs.

QB3 will be run until 30 June by Graham Fleming, director of physical biosciences at UC Berkeley. Officials are exploring options for QB3's directorship after then. 